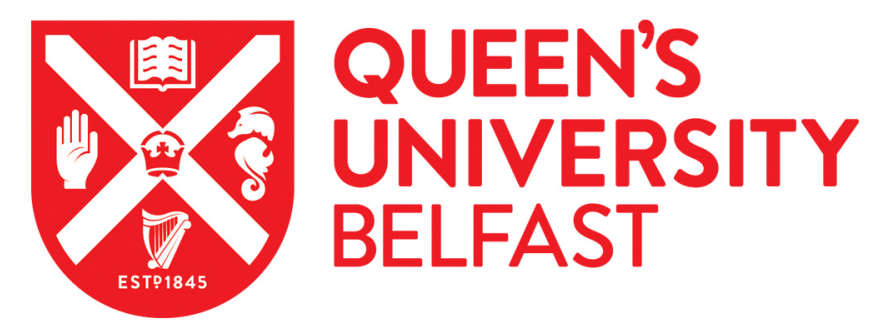

\title{
A feasibility study of auricular therapy and self-administered acupressure for insomnia following cancer treatment
}

Hughes, J. G., Towler, P., Storey, L., Wheeler, S. L., \& Molassiotis, A. (2015). A feasibility study of auricular therapy and self-administered acupressure for insomnia following cancer treatment. European Journal of Integrative Medicine, 7(6), 623-627. https://doi.org/10.1016/j.eujim.2015.08.003

Published in:

European Journal of Integrative Medicine

Document Version:

Peer reviewed version

Queen's University Belfast - Research Portal:

Link to publication record in Queen's University Belfast Research Portal

Publisher rights

(c) Elsevier 2015. Published by Elsevier $\mathrm{GmbH}$.

This manuscript version is made available under the CC-BY-NC-ND 4.0 license (http://creativecommons.org/licenses/by-nc-nd/4.0/), which permits distribution and reproduction for non-commercial purposes, provided the author and source are cited.

\section{General rights}

Copyright for the publications made accessible via the Queen's University Belfast Research Portal is retained by the author(s) and / or other copyright owners and it is a condition of accessing these publications that users recognise and abide by the legal requirements associated with these rights.

Take down policy

The Research Portal is Queen's institutional repository that provides access to Queen's research output. Every effort has been made to ensure that content in the Research Portal does not infringe any person's rights, or applicable UK laws. If you discover content in the Research Portal that you believe breaches copyright or violates any law, please contact openaccess@qub.ac.uk. 


\section{Accepted Manuscript}

Title: A feasibility study of auricular therapy and self-administered acupressure for insomnia following cancer treatment

Author: John Gareth Hughes Penny Towler Lesley Storey Sara Louise Wheeler Alex Molassiotis

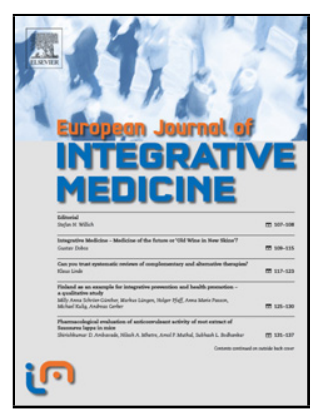

PII: S1876-3820(15)30025-1

DOI: http://dx.doi.org/doi:10.1016/j.eujim.2015.08.003

Reference: EUJIM 439

To appear in:

Received date: $\quad 16-4-2015$

Revised date: $\quad 11-8-2015$

Accepted date: $\quad$ 13-8-2015

Please cite this article as: Hughes John Gareth, Towler Penny, Storey Lesley, Wheeler Sara Louise, Molassiotis Alex.A feasibility study of auricular therapy and selfadministered acupressure for insomnia following cancer treatment.European Journal of Integrative Medicine http://dx.doi.org/10.1016/j.eujim.2015.08.003

This is a PDF file of an unedited manuscript that has been accepted for publication. As a service to our customers we are providing this early version of the manuscript. The manuscript will undergo copyediting, typesetting, and review of the resulting proof before it is published in its final form. Please note that during the production process errors may be discovered which could affect the content, and all legal disclaimers that apply to the journal pertain. 
Title: A feasibility study of auricular therapy and self-administered acupressure for insomnia following cancer treatment

John Gareth Hughes, ${ }^{1}$ Penny Towler, ${ }^{2}$ Lesley Storey, ${ }^{3}$ Sara Louise Wheeler, ${ }^{4}$ Alex Molassiotis. ${ }^{2,5}$

${ }^{1}$ Royal London Hospital for Integrated Medicine, UCLH NHS Trust, London, UK

${ }^{2}$ School of Nursing, Midwifery \& Social Work, University of Manchester, Manchester, UK

${ }^{3}$ School of Psychology, Queen's University, Belfast, UK

${ }^{4}$ School of Social Sciences, Bangor University, Bangor, UK

${ }^{5}$ School of Nursing, The Hong Kong Polytechnic University, Hong Kong

Email addresses:

John.Hughes@uclh.nhs.uk

pennytowler@googlemail.com

1.storey@qub.ac.uk

s.wheeler@bangor.ac.uk

alex.molasiotis@polyu.edu.hk

Word total: 2549

Sources of funding: The feasibility study was funded through a Cancer Experiences Collaborative (CECo) small grant.

Corresponding author contact details:

Dr John Hughes

Senior Research Co-ordinator

Royal London Hospital for Integrated Medicine

60 Great Ormond Street

London WC1N 3HR

Tel: $+44(0) 2034488883$

Fax: +44 (0)2073918869.

Email: John.Hughes@uclh.nhs.uk

\section{Abstract}

Introduction: Many cancer patients experience sleeping difficulties which can persist several years after the completion of cancer treatment. Previous research suggests that acupuncture, and variants of acupuncture (acupressure, auricular therapy) may be effective treatment options for sleep disturbance. However, current evidence is limited for cancer patients.

Methods: Feasibility study with 3 arms. Seven cancer patients with insomnia randomised to receive either auricular therapy (attaching semen vaccariae seeds to ear acupoints) ( $n=4)$, selfacupressure $(n=1)$ or no treatment $(n=2)$. Participants assigned to receive auricular therapy or selfacupressure stimulated the acupoints each night an hour before retiring to bed. The duration of participant involvement was 5 weeks. Subjective sleep quality was measured at baseline and posttreatment using the Pittsburgh Sleep Quality Index (PSQI). The impact of treatment on concerns of importance to the participants themselves was measured using the Measure Yourself Concerns and Wellbeing (MYCaW). Each participant also completed a treatment log book. 
Results: All participants completed their treatment. All auricular therapy and self-acupressure participants recorded clinically significant improvements in global PSQI scores. In the auricular therapy arm mean global PSQI reduced from 12.5 at baseline to 8 following completion of treatment. In the self-acupressure arm PSQI reduced from 15 to 11 . While in the no treatment arm the mean PSQI score was 14.5 at both baseline and follow up.

Conclusions: Despite the limited sample size, both auricular therapy and self-acupressure may represent potentially effective treatments for cancer patients with insomnia. The positive findings suggest further research is warranted into both treatment modalities.

Keywords:

Cancer, insomnia, auricular therapy, acupressure.

Introduction:

Between $25 \%$ and $59 \%$ of cancer patients experience sleeping difficulties [1-4]. Patients ranked sleep problems as the $5^{\text {th }}$ highest out of 14 distressing symptoms before their cancer treatment, and $4^{\text {th }}$ highest after cancer treatment [5]. In between $23 \%$ and $44 \%$ of cancer patients, sleep problems persist several years after the initiation of adjuvant therapy for cancer, suggesting that insomnia develops a chronic course in substantial numbers of cancer patients [6]. Many of these cancer patients receive hypnotic medications to relieve their symptoms of insomnia. However, the usage of hypnotic medications is associated with a number of risks and limitations, such as daytime drowsiness and associated increased risk of falls and fractures [6]. Prolonged usage is also associated with risks of dependence or tolerance (reduced efficacy due to prolonged usage, and the need to increase the dosage to maintain therapeutic effects) [6]. Given the limitations of hypnotic medications non-pharmacologic approaches to treating insomnia should be considered.

The findings from published systematic reviews suggest that acupuncture, and variants of acupuncture (acupressure; auricular acupuncture; auricular therapy), may be effective treatment options for sleep disturbance [7-13]. However, evidence of the effectiveness of acupuncture and related interventions within cancer are more limited [14]. A non-randomised single arm feasibility study evaluated a short course of acupuncture treatment for sleep disturbance and hot flushes in 10 postmenopausal breast cancer survivors. The findings suggested a short term benefit from acupuncture on a range of sleep outcomes (total sleep time, sleep latency, and night-time awakenings) [15]. A randomized controlled trial comparing acupuncture with fluoxetine in 80 cancer patients presenting with depression and insomnia concluded that acupuncture significantly improved sleep quality [16].

However many previous studies of acupuncture and related interventions have contained numerous methodological weaknesses [7-16], and there is no conclusive evidence to suggest which modality of acupuncture may be more effective for sleep disturbance. This feasibility study aimed to address this gap in the evidence base and provide preliminary data on the effectiveness of two variants of acupuncture (auricular therapy (attaching semen vaccariae seeds to ear acupoints) and selfadministered acupressure) in the relief of insomnia in a sample of patients with cancer in a methodologically rigorous feasibility study.

Methods: 
The study was a randomised controlled feasibility study with 3 arms. Treatment arms consisted of (1) auricular therapy (attaching semen vaccariae seeds to ear acupoints), (2) self-administered acupressure, and (3) no additional treatment. Patients were informed about the study by treating healthcare professionals at the study site. Members of the research team provided interested patients with a patient information sheet and detailed verbal information regarding the study. Participants were required to be hospital outpatients with breast, prostate or colorectal cancer; meet the criteria for chronic insomnia syndrome (require more than thirty minutes to fall asleep and/or have more than thirty minutes of nocturnal awakenings, occurring three nights a week or more, for six months or more and affecting daytime functioning); have a score of five or more on the Pittsburgh Sleep Quality Index; be older than 16 years; and receiving acupressure or auricular therapy for the first time. Exclusion criteria included those with self-reported sleeping difficulties prior to receiving their diagnosis of cancer; those currently receiving, or having received within the last month, chemotherapy or radiotherapy; and those scheduled to receive anticancer treatments within the next three months, with the exception of adjuvant hormone therapy. Patient recruitment occurred between February 2010 and June 2012.

The duration of participants' involvement was 5 weeks. Participants were randomly allocated to the trial groups through simple envelope method. Trial allocations were randomly placed in sealed numbered opaque envelopes by a member of university staff not involved in the research study or the care of the participating patients. Upon participants consenting to take part in the study the next numbered envelope was opened to reveal the trial allocation.

As part of the feasibility study aspects of the study design, such as recruitment, acceptability of the intervention, and appropriateness of the outcome measures were evaluated. The study was conducted at the Christie NHS Foundation Trust, Manchester. Ethical approval for the feasibility study was obtained from Stafford and Trafford Research Ethics Committee [REC reference number: 09/H1004/7].

\section{Interventions:}

Participants were randomly allocated to receive either auricular therapy, self-administered acupressure, or no treatment. The modalities of acupressure and auricular therapy were chosen for this study due to considerations of ease of administration, and because they are less invasive than needle insertion. The acupuncturists instructing patients and administering treatments were all nurses who had received training from either the British Medical Acupuncture Society or the British Academy of Western Medical Acupuncture. All acupuncturists had at least 3 years of clinical experience in treating patients with cancer.

Auricular therapy: participants assigned to auricular therapy attended Christie NHS Foundation Trust on a weekly basis for five weeks. Appointment times lasted approximately ten minutes and took place at a time convenient for participants (total therapist contact time 50min). Acupoints selected for the feasibility study were based on those utilised in previous research; acupuncture textbooks; and consultations with practicing acupuncturists. The auricular acupoints stimulated included shenmen bilaterally, and any two from insomnia 1, insomnia 2, heart, liver, kidney and subcortex bilaterally based on the patient's presenting condition. Semen vaccariae seeds were fixed tightly to each acupoint with a piece of adhesive plaster by the treating acupuncturist. The seeds were left in place and replaced each week by the acupuncturist. Based on previous research and consultations with practicing acupuncturists, participants were asked to press the seeds for one minute each night an hour before retiring to bed.

Self-administered acupressure: Participants allocated to the self-administered acupressure group received a 50 min appointment with an acupuncturist, at a time convenient for the participant. The 
acupuncturist provided participants with instructions on how to locate and apply pressure to specific acupoints. Acupoints selected for the feasibility study were based on points used within previous research; consulting acupuncture/acupressure textbooks; and consultations with practicing acupuncturists. Consideration was additionally given to the likely ease of location and stimulation by patients. All patients were instructed to apply pressure to HT7 bilaterally, and two from PC6, GB20, Ex8 (anmian 1), KI6, BL62 bilaterally based on the patients presenting condition. Based on previous research and consultations with practicing acupuncturists, participants were asked to stimulate each acupoint for approximately one minute, each evening an hour before retiring to bed.

No additional treatment: Participants allocated to the no treatment group received no additional treatments for the duration of the study. Participants allocated to no additional treatment were offered the choice of receiving either auricular therapy or self-acupressure at the end of their participation in the study.

Outcome measures:

Subjective sleep quality was measured using the Pittsburgh Sleep Quality Index (PSQI) [17], which contains seven indices to represent patients' quality of sleep over the previous month: overall sleep quality; sleep latency (the amount of time it takes to fall asleep); sleep duration; sleep efficiency; sleep disturbances; day dysfunction due to sleepiness; and use of sleeping medication. Global PSQI scores range from 0 to 21 , with a score of $\geq 5$ indicating sleeping difficulty. In addition the impact of treatment on concerns of importance to the participants' themselves were measured using the Measure Yourself Concerns and Wellbeing (MYCaW) [18]. The MYCaW is an individualised questionnaire that has been developed for evaluating complementary therapies in cancer care. MYCaW contains two patient-generated problems. Patients rate two concerns or problems which they would most like help with using a seven point likert scale, with 0 being 'not bothering me at all' and 6 being 'bothers me greatly'. MYCAW also contains an overall measurement of wellbeing, also rated on a seven point likert scale with 0 being 'as good as it could be' and 6 being 'as bad as it could be'.

Participants completed the PSQI and MYCaW with a member of the research team at baseline, and self-completed the questionnaires five weeks later at the end of the study intervention. Participants also completed a log book documenting their use and experience of conventional and unconventional treatments for sleep disturbance during the study (including auricular therapy and self-administered acupressure if assigned to one of these groups).

Population sample:

The planned sample for the study was a stratified sample of 18 hospital outpatients ( 6 breast cancer patients, 6 prostate cancer patients, 6 colorectal cancer patients). However, due to recruitment difficulties only 7 participants were recruited. 4 participants were randomised to receive auricular therapy, 1 self-acupressure, and 2 no additional treatment. Five participants were diagnosed with breast cancer, and 2 with colorectal cancer. The age range of the participants was 43 to 71 (mean 55), 6 were female and 1 male. See Table 1 for sociodemographic characteristics of participants.

\section{INSERT TABLE 1 HERE}

Results:

Data from the log books indicate that participants allocated to auricular therapy and selfacupressure largely administered the treatments as instructed on a nightly basis. One auricular therapy participant reported forgetting to apply the intervention on three evenings, whilst another 
auricular therapy participant reported purposely not pressing the ear seeds on three separate evenings, to test if there was continuation of the improvement in sleep that had been experienced.

One participant allocated to auricular therapy contracted shingles during the study and received painkillers, antiviral medication and antidepressants. No other pharmacological interventions were taken by participants during the study. Apart from the trial interventions, the only non pharmacological methods that participants reported using to help with sleep were warm milky drinks and bubble baths. Two participants reported some ear tenderness from the auricular therapy, although this did not appear to cause distress or be long lasting. Two of the participants described individual seeds falling off, and both of them reported pressing the site where the seed had been instead until the seed was replaced. Participants receiving active treatments commented in their log books that they had positive perceptions of the experience of undertaking the therapy and the effect the treatment had on their sleep.

It had been intended that data from the PSQI and MYCaW would be inputted into Statistical Packages for Social Sciences (SPSS) and analysed using appropriate between-group tests. However, due to the small sample size achieved only the mean improvement in scores is presented. Mean global PSQI score improved by 4.5 in the auricular therapy group, by 4 in the selfacupressure group, and did not change in the no additional treatment group. For the auricular therapy group improvements in PSQI scores were seen in duration of sleep, day dysfunction due to sleepiness, sleep efficacy, and overall sleep quality. In the self-acupressure participant improvements were seen in sleep latency, sleep disturbance, and overall sleep quality.

All participants listed an improvement to their sleep as their primary concern when completing the MYCaW questionnaire. Mean MYCaW score for sleep reduced by 2.25 in the auricular therapy arm, by 2 in the self-acupressure arm, and increased by 0.5 in the no additional treatment arm. Participants' second item of concern included anxiety, fatigue, and pain. In both the auricular therapy arm and the self-acupressure arm the mean reduction in the second item of concern to participants reduced by 1 , while the score for the no additional treatment arm remained the same.

See Table 2 for all mean baseline and post-treatment scores.

\section{INSERT TABLE 2 HERE}

\section{Discussion:}

To the authors knowledge the present feasibility study of auricular therapy and self-acupressure is one of the first studies to evaluate these modalities for insomnia in cancer patients. All participants allocated to auricular therapy or self-acupressure completed the intervention, with only minor issues with ear tenderness reported by two auricular therapy participants, suggesting that both interventions are acceptable to cancer patients. The PSQI and MYCAW appeared to be appropriate tools to use and were completed by participants with no concerns raised. The tools were sensitive to reported changes in sleeping patterns and the scores of the two tools corresponded, ie, changes or similar scores in the PSQI were reflected in the scores of the MYCAW. Recruitment rates for the study were lower than anticipated, and are a major limitation of the current study. The key problem was that, despite current evidence suggesting that between $23 \%$ and $44 \%$ of cancer patients develop symptoms of chronic insomnia following treatment for cancer [6], the present study found very low rates of cancer patients reporting insomnia to their treating healthcare practitioner. However, there is evidence that people often do not report their experience of insomnia to their health professionals [22], which may have further hindered recruitment in this study. A large number of those patients who did present with insomnia were also ineligible to participate, due to currently receiving, or having received in the previous month, chemotherapy 
and/or radiotherapy. It may be advisable for future studies to either expand inclusion criteria to include those receiving chemotherapy and/or radiotherapy, or target post active treatment patients through alternative sites, such as GP practices.

A reduction of 3 points on global PSQI is considered a clinically significant reduction $[17,19,20]$, and it is noteworthy that all 5 participants allocated to receive either auricular therapy or selfacupressure had a reduction of 3 or more in global PSQI scores. Although the sample size was very small, it may also be noteworthy that those who received auricular therapy reported different improvements in insomnia symptoms to the participant who received self-acupressure. While participants in both groups saw an improvement in overall sleep quality, the four participants who received auricular therapy noted improvements in the duration of sleep, day dysfunction due to sleepiness, and sleep efficacy; whereas the one self-acupressure participant noted a reduction in sleep latency and sleep disturbance, which may be an interesting hypothesis to explore in future research.

The clinical improvement seen in patients receiving auricular therapy or self-acupressure is comparable to that seen in previous studies of acupuncture and related interventions in patients with different presenting conditions. In the Cochrane systematic review by Cheuk et al [8] the findings from 5 randomised controlled trials of acupressure versus no additional treatment which had utilised the PSQI were collectively analysed. The 5 trials included a diverse range of patient populations including those with depression/anxiety, renal disease, and haemodialysis patients. Their findings showed that the global PSQI score was better in the acupressure group compared to the no treatment group $(\mathrm{P}<0.00001)$, with the mean reduction of PSQI score being 3.17 greater in the acupressure group compared to the no additional treatment group. Similar improvements have been reported for trials of auricular therapy for insomnia. Wang et al [21] reported a mean greater improvement of 2.5 in global PSQI score compared to no treatment in nursing students with an initial PSQI score of 5 or more. However, all the trials contained methodological weaknesses, with Cheuk et al [8] noting that the trials contained within their review had a high risk of bias and were heterogeneous in their definition of insomnia, participant characteristics, acupoints and treatment.

Despite the very limited sample size, all patients allocated to receive either auricular therapy or self-acupressure experienced clinically relevant improvements in their symptoms of insomnia. Both auricular therapy and self-acupressure are non-invasive interventions, which appear safe and acceptable to cancer patients, and may represent effective treatments for chronic insomnia syndrome. Further large scale trials of both interventions are warranted to establish the effectiveness of auricular therapy and self-acupressure for insomnia in cancer patients.

\section{Conflict of interest:}

The authors declare they have no competing interests.

Acknowledgements:

The authors wish to thank the acupuncturists at Christie NHS Foundation Trust for administering treatments during the study, the patients who kindly participated in the study, and the Cancer Experiences Collaborative (CECo) for funding the research.

\section{References}

[1] Davidson JR, MacLean AW, Brundage MD, Schulze K. Sleep disturbance in cancer patients. Soc Sci Med 2002; 54: 1309-21.

[2] Savard J, Villa J, Ivers H, Simard S, Morin CM. Prevalence, natural course, and risk factors of insomnia comorbid with cancer over a 2-month period. J Clin Oncol 2009; 27: 5233-9. 
[3] Palesh O, Roscoe J, Mustian K, Roth T, Savard J, Ancoli-Israel S, et al. Prevalence, demographics, and psychological associations of sleep disruption in patients with cancer: University of Rochester Cancer Centre- Community clinical oncology program. J Clin Oncol 2010; 28: 292-8.

[4] Savard J, Ivers H, Villa J, Caplette-Gingras A, Morin CM. Natural course of insomnia comorbid with cancer: an 18-month longitudinal study. J Clin Oncol 2011; 29: 3580-6.

[5] Munro AJ, Potter S. A quantitative approach to the distress cased by symptoms in patients treated with radical radiotherapy. Br J Cancer 1996; 74: 640-7.

[6] Savard J, Morin CM. Insomnia in the context of cancer: a review of a neglected problem. J Clin Oncol 2001; 19: 895-908.

[7] Chen HY, Shi Y, Ng CS, Chan SM, Yung KK, Zhang QL. Auricular acupuncture treatment for insomnia: a systematic review. J Altern Complement Med 2007; 13: 669-76.

[8] Cheuk DKL, Yeung WF, Chung KF, Wong V. Acupuncture for insomnia. Cochrane Database of Systematic Reviews 2012, Issue 9. Art. No.: CD005472. DOI: 10.1002/14651858.CD005472.pub3.

[9] Kalavapalli R, Singareddy R. Role of acupuncture in the treatment of insomnia: a comprehensive review. Complement Ther Clin Pract 2007; 13: 184-193.

[10] Cao H, Pan X, Li H, Liu J. Acupuncture for treatment of insomnia: a systematic review of randomized controlled trials. J Altern Complement Med 2009; 15: 1171-86.

[11] Huang W, Kutner N, Bliwise DL. A systematic review of the effects of acupuncture in treating insomnia. Sleep Med Rev 2009; 13: 73-104.

[12] Yeung WF, Chung KF, Poon MM, Ho FY, Zhang SP, Zhang ZJ, et al. Acupressure, reflexology, and auricular acupressure for insomnia: a systematic review of randomized controlled trials. Sleep Med 2012; 13: 971-84.

[13] Yeung WF, Chung KF, Leung YK, Zhang SP, Law AC. Traditional needle acupuncture treatment for insomnia: a systematic review of randomized controlled trials. Sleep Med 2009; 10: 694-704.

[14] 1. Towler P, Molassiotis A, Brearley SG. What is the evidence for the use of acupuncture as an intervention for symptom management in cancer supportive and palliative care: an integrative overview of reviews. Support Care Cancer 2013; 21: 2913-23.

[15] Otte JL, Carpenter JS, Zhong X, Johnstone PA. Feasibility study of acupuncture for reducing sleep disturbance and hot flashes in postmenopausal breast cancer survivors. Clin Nurse Spec 2011; 25: 228-36.

[16] Feng Y, Wang XY, Li SD, Zhang Y, Wang HM, Li M, et al: Clinical research of acupuncture on malignant tumor patients for improving depression and sleep quality. J Tradit Chin Med 2011; 31: 199-202.

[17] Buysse DJ, Reynolds CF, Monk TH, Berman SR, Kupfer DJ. The Pittsburgh sleep quality index: a new instrument for psychiatric practice and research. Psychiatry Res 1989; 28: 193-213.

[18] Paterson C, Thomas K, Manasse A, Cooke H, Peace G. Measure yourself concerns and wellbeing (MYCaW): an individualised questionnaire for evaluating outcome in cancer support care that includes complementary therapies. Complement Ther Med 2007; 15: 38-45.

[19] Hughes CM, McCullough CA, Bradbury I, Boyde C, Hume D, Yuan J, et al. Acupuncture and reflexology for insomnia: a feasibility study. Acupunct Med 2009; 27: 163-8.

[20] Morgan K, Dixon S, Mathers N, Thompson J, Tomeny M. Psychological treatment for insomnia in the management of long-term hypnotic drug use: A pragmatic randomised controlled trial. Br J Gen Pract 2003; 53: 923-8.

[21] Wang H, Yeh M, Chung U, Yang C. Improving sleep quality: the efficacy of auricular acupressure. J Evid Based Nurs 2008; 4: 243-50.

[22] Davidson JR, Feldman-Stewart D, Brennenstuhl S, Ram S. How to provide insomnia interventions to people with cancer: insights from patients. Psychooncology 2007; 16: 1028-38. 
Table 1 Sociodemographic characteristics of participants

\begin{tabular}{|c|c|c|c|c|c|c|c|c|c|}
\hline Participant & Gender & Age & $\begin{array}{c}\text { Cancer } \\
\text { diagnosis }\end{array}$ & $\begin{array}{c}\text { Ethnic } \\
\text { origin }\end{array}$ & $\begin{array}{c}\text { Marital } \\
\text { Status }\end{array}$ & $\begin{array}{c}\text { Educational } \\
\text { Level }\end{array}$ & $\begin{array}{c}\text { Occupational } \\
\text { group }\end{array}$ & $\begin{array}{c}\begin{array}{c}\text { Occupational } \\
\text { status }\end{array} \\
\end{array}$ & Intervention \\
\hline $\mathrm{A} 01$ & Female & 45 & Breast & Caucasian & Married & $\begin{array}{l}\text { College/ } \\
\text { diploma }\end{array}$ & $\begin{array}{l}\text { Skilled non } \\
\text { manual }\end{array}$ & $\begin{array}{c}\text { Not working } \\
\text { due to ill } \\
\text { health }\end{array}$ & $\begin{array}{l}\text { Auricular } \\
\text { therapy }\end{array}$ \\
\hline $\mathrm{A} 02$ & Female & 71 & Breast & Caucasian & Married & $\begin{array}{l}\text { College/ } \\
\text { diploma }\end{array}$ & Professional & Retired & $\begin{array}{c}\text { Self- } \\
\text { acupressure }\end{array}$ \\
\hline $\mathrm{A} 03$ & Female & 51 & Breast & Caucasian & Married & $\begin{array}{l}\text { University/ } \\
\text { degree }\end{array}$ & Professional & $\begin{array}{l}\text { Employed } \\
\text { part-time }\end{array}$ & $\begin{array}{l}\text { Auricular } \\
\text { therapy }\end{array}$ \\
\hline A04 & Female & 56 & Breast & Caucasian & Married & $\begin{array}{l}\text { Secondary } \\
\text { School }\end{array}$ & Unskilled & Unemployed & $\begin{array}{l}\text { No additional } \\
\text { treatment }\end{array}$ \\
\hline A05 & Male & 70 & Colorectal & Caucasian & Married & $\begin{array}{c}\text { Secondary } \\
\text { School }\end{array}$ & Skilled manual & Retired & $\begin{array}{l}\text { Auricular } \\
\text { therapy }\end{array}$ \\
\hline A06 & Female & 52 & Colorectal & Caucasian & Married & $\begin{array}{l}\text { College/ } \\
\text { diploma }\end{array}$ & Professional & Retired & $\begin{array}{l}\text { No additional } \\
\text { treatment }\end{array}$ \\
\hline A07 & Female & 43 & Breast & $\begin{array}{l}\text { Data not } \\
\text { available }\end{array}$ & $\begin{array}{l}\text { Data not } \\
\text { available }\end{array}$ & $\begin{array}{l}\text { Data not } \\
\text { available }\end{array}$ & $\begin{array}{l}\text { Data not } \\
\text { available }\end{array}$ & $\begin{array}{l}\text { Data not } \\
\text { available }\end{array}$ & $\begin{array}{l}\text { Auricular } \\
\text { therapy }\end{array}$ \\
\hline
\end{tabular}

Table 2 Mean baseline and post-treatment scores

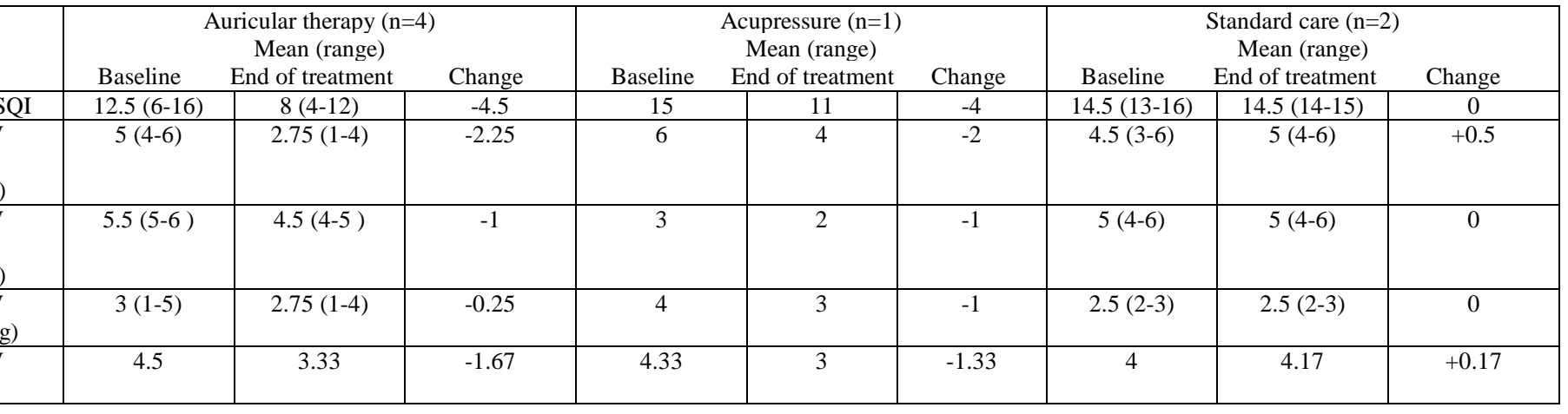

*MYCAW profile scores are the mean of the concerns and wellbeing scores combined. 